\title{
Psicologia e teoria das representações sociais Sertão: contextos e representações, tendo em vista as representações sociais de sertão entre moradores de Petrolina (PE) e Juazeiro (BA)
}

Liliane Caraciolo Ferreira

Lídio Souza

\section{SciELO Books / SciELO Livros / SciELO Libros}

FERREIRA, L.C., and SOUZA, L. Sertão: contextos e representações, tendo em vista as representações sociais de sertão entre moradores de Petrolina (PE) e Juazeiro (BA). In: SANTIAGO, A.M.S., and FONSÊCA, A.L.B., comp. Psicologia e suas interfaces: estudos interdisciplinares [online]. Salvador: EDUFBA, 2016, pp. 255-274. ISBN 978-85-232-2007-5.

https://doi.org/10.7476/9788523220075.0011.

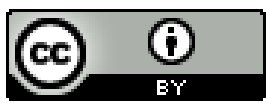

All the contents of this work, except where otherwise noted, is licensed under a Creative Commons Attribution 4.0 International license.

Todo o conteúdo deste trabalho, exceto quando houver ressalva, é publicado sob a licença Creative Commons Atribição $\underline{4.0}$. 


\section{Sertão: contextos e representações, tendo em vista as representações sociais de sertão entre moradores de Petrolina (PE) e Juazeiro (BA)}

Liliane Caraciolo Ferreira, Lídio Souza

Introdução

Há muito, é reconhecido que o fenômeno climático que assola o sertão assume dimensões de calamidade pública devido à situação de pobreza em que vive a maioria da população dessa região brasileira. (COELHO; SANTOS, 2005; DUARTE, 2001; LIMA, 2008; MATTAR; VILELA, 2010; SÁ, 2003; SILVA, 2007) Tratando do tema, muita tinta já foi gasta na academia, na arte, nas políticas públicas e na mídia. $\mathrm{Na}$ academia, por exemplo, podemos citar, entre outras, as disciplinas de Geografia, História, Economia, Literatura, Antropologia, Sociologia. Na literatura, sertão e sertanejos são temas frequentes em livros, literatura de cordel e quadrinhos. Na mídia, em rádio, jornal e televisão. Na arte, as referências encontram-se nos quadros, na música, 
no cinema e em peças de teatro. Como exemplo, temos a marcante recorrência do "cangaço" nas mais "diversas produções culturais (folhetos de cordel, xilogravuras, folclore, romances, cinema, quadrinhos)". (SÁ, 2003)

Para Gomes (2008, p. 11), “[...] cada sociedade elege o núcleo de preocupações ao qual confere centralidade". No caso do Brasil, o sertão é tema antigo, visto que já ocupava a mente dos portugueses que aqui se instalaram e depararam com o desconhecido. É notório que ainda hoje o tema ocupe a mente dos brasileiros e, em especial, dos governantes, tendo em vista que estamos falando da região com os maiores índices de pobreza do país. Segundo o Instituto de Pesquisa Econômica Aplicada (Ipea) (2011), 52,47\% dos domicílios nordestinos, em 2009, estavam abaixo da linha de pobreza. Cenário persistente, conforme os dados de 1981 a 2009 (Figura 1).

Figura 1 - Percentual de domicílios em pobreza por região no Brasil (1981 - 2009)

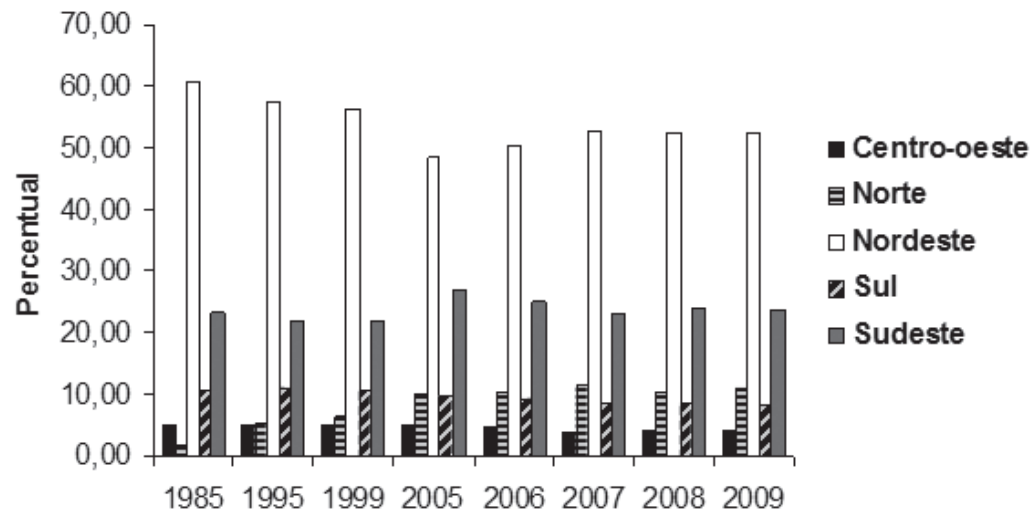

Fonte: Instituto de Pesquisa Econômica Aplicada (2012).

É necessário que se faça uma breve exposição da transferência de recursos para atender a região Nordeste. O recorte que nos orienta é “a seca”, tendo em vista que, até a primeira metade do século XIX, ela foi considerada um problema para o projeto de colonização, porque índios fugiam para o litoral em busca de alimentos. Na condição 
de "assunto de índio", a fome e a miséria no sertão seriam registradas como um problema para a "civilização" ou, especificamente, para o "projeto de colonização", até que o sertão fosse povoado pelos brancos, com fazendas de gado que seriam atingidas por longos períodos de seca, e o que era "problema de índio" passasse a ser "prejuízo de fazendeiros”. Ciência, governo, fazendeiros e políticos são alguns dos setores que se mobilizaram para "a nova perspectiva de atendimento à região”. (SILVA, 2007, p. 472)

A partir dessa preocupação em atender fazendeiros, podemos compreender a gradativa evolução de possíveis transferências de recursos para o Nordeste e especificamente para a região Petrolina-PE/ Juazeiro-BA. Na lógica capitalista, para que o modelo de produção funcione é preciso acumular capital, e isso ocorre com o excedente de produção e os meios para escoar o produto, tais como estradas, portos, aeroportos, transportes e comunicação.

É importante lembrar que o tema sertão foi eleito pelos portugueses e permanece até hoje como um "problema” para o governo. Diante dessa amplitude temporal, da colonização à industrialização da economia brasileira, este trabalho procurou orientar-se por dois momentos da História do Brasil, o colonial e o pós-colonial, e suas influências na elaboração de representações, ou seja, "dos elementos socioculturais que influenciam" o trabalho de quem cria significados. (GUEDES, 2006)

No período colonial, o primeiro significado do sertão surgiu com a chegada dos portugueses, que ocuparam o solo a partir do litoral e nomearam as terras além de sertão, ou seja, terras "desertas”, "desconhecidas" e "perigosas". Uma vez instalados no litoral, evoluiriam de povoado para cidade e o significado de sertão passou a ser construído em relação ao que estava colonizado (o litoral), seria o não colonizado ou incivilizado. Seguiu-se com a exploração e povoamento do sertão e, com as "entradas e bandeiras", foi descoberto o ouro e instalou-se a criação de gado, cenário de um novo ciclo de significados: sertões do ouro e sertões dos currais. (IBGE, 2006) 
Essa ideia de ocupação e exploração foi substituída pela perspectiva instaurada pela declaração da independência do Brasil, que cria e difunde a ideia de nação, instituindo-se um novo campo de representações: os ideais de “brasilidade”. (ARRUDA 2005) É no período pós-colonial que o sertão passa por construções conduzidas por dois movimentos: o Romantismo e o Realismo. A urgência em caracterizar a ex-colônia fez com que o brasileiro fosse associado à paisagem e à sociedade do interior, numa perspectiva romântica: Araújo (2008, p. 24-25), citando, Guimarães Rosa (2008, p. 23-24), diz:

O país não poderia ser definido moral e culturalmente a partir do ambiente eclético, heterogêneo e indefinível que se encontra à beira-mar. Para o autor, a chave para adentrarmos as características nacionais só será encontrada nas estradas que levam ao interior do país. Somente neste ambiente distante das diversas influências metropolitanas e estrangeiras em geral, com a rigidez e proximidade do controle português é que se pode encontrar o brasileiro digno desta definição.

Por sua vez, para o Realismo, a região era tida como um problema para a nação que se desejava construir, um outro negativo, oposto à urbanidade litorânea, porção indesejável e vergonhosa do Brasil, a exemplo da descrição do sertanejo por Euclides da Cunha (1901, p. 51) em Os sertões: "É homem permanentemente fatigado."

Vale lembrar que o critério de análise que aqui é utilizado tem em vista as construções e reconstruções de representações em determinados momentos ou contextos. O nacionalismo romântico brasileiro, por exemplo, sofreu influência do nacionalismo romântico europeu. Segundo Antônio Cândido (2004, p. 13): “No Brasil, ao contrário dos países americanos que conheceram grandes civilizações pré-colombianas, é impossível pensar num processo civilizador à margem da conquista européia, que criou o País”. 
Para aprofundar o entendimento, vale a reflexão sobre explicações biológico-raciais que elegeram a miscigenação como símbolo de degeneração da raça humana e influenciou o realismo brasileiro. Cientistas como Nina Rodrigues, médico legista, professor de Medicina Legal na Bahia, Oliveira Viana, professor da Faculdade de Direito do Rio de Janeiro, e Euclides da Cunha, engenheiro, cientista e literário, incorporaram e difundiram a teoria do racismo no Brasil. (BUONICORE, 2005)

Mesmo que não seja o objetivo desse trabalho, entende-se que é relevante refletir sobre o papel do cientificismo ${ }^{1}$ biológico-racial no processo de construção histórica de uma forma de pensar legitimada, mesmo que breve. São exemplos dessa construção: Gobineau (18161882) e a superioridade da raça branca, Ratzel (1884-1904) e a divisão dos povos entre naturais e civilizados, e Lombroso (1835-1909), que procurou estabelecer relações entre características físicas e tendências criminais.

No caso brasileiro, tais influências podem ser identificadas em Nina Rodrigues (1862-1946) e a teoria sobre a tendência de negros e mestiços ao crime. Euclides da Cunha (1866-1909) e a teoria dos dois brasis: atrasado e moderno. Oliveira Viana (1883-1951), por sua vez, com sua teoria de negros e índios como massas passivas e improgressivas (Quadro 1).

1 Entende-se por cientificismo quando a ciência é reduzida à verificação empírica, ignnorando qualquer outro método de investigaação como científica. 
Quadro 1 - 0 papel do cientificismo biológico-racial na construção do racismo (século XIX - século XX)

\begin{tabular}{|c|c|c|c|}
\hline INTELECTUAIS & $\begin{array}{l}\text { ATIVIDADE } \\
\text { PROFISSIONAL }\end{array}$ & $\begin{array}{l}\text { PAÍS DE } \\
\text { ORIGEM }\end{array}$ & TEORIA \\
\hline $\begin{array}{l}\text { Joseph Arthur } \\
\text { de Gobineau } \\
\text { (1816-1882) }\end{array}$ & $\begin{array}{l}\text { Diplomata, escritor } \\
\text { e filósofo. }\end{array}$ & França & $\begin{array}{l}\text { Tese sobre a existência de uma } \\
\text { superioridade inata das raças brancas e } \\
\text { louras (arianas) sobre todas as outras. } \\
\text { A miscigenação é inevitável e levará a } \\
\text { raça humana a graus sempre maiores de } \\
\text { degenerescência física e intelectual. Obra: } \\
\text { Ensaio sobre a desigualdade das raças } \\
\text { humanas (1855). }\end{array}$ \\
\hline $\begin{array}{l}\text { Friedrich Ratzel } \\
(1884-1904)\end{array}$ & Geógrafo e etnólogo. & Alemanha & $\begin{array}{l}\text { Dividiu os povos em dois grandes } \\
\text { grupos, "naturais" e "civilizados". Os } \\
\text { primeiros eram dominados pela natureza } \\
\text { e os segundos a dominavam. O meio } \\
\text { influencia a história humana na medida } \\
\text { em que pode oferecer melhor ou pior } \\
\text { acesso aos recursos naturais, atuando } \\
\text { assim como estímulo ou obstáculo ao } \\
\text { progresso. Obras: Antropogeografia } \\
\text { (1882); As raças humanas (1885 e 1888); } \\
\text { Geografia política (1897). }\end{array}$ \\
\hline $\begin{array}{l}\text { Cesare } \\
\text { Lombroso } \\
(1835-1909)\end{array}$ & $\begin{array}{l}\text { Professor de } \\
\text { psiquiatria e } \\
\text { Medicina Forense. }\end{array}$ & Itália & $\begin{array}{l}\text { Tentativa de dar status científico ao } \\
\text { racismo moderno. Tese da relação entre } \\
\text { as características físicas dos indivíduos } \\
\text { e sua capacidade mental e propensões } \\
\text { morais. Obras: O homem delinquente } \\
\text { (1876); } \\
\text { O crime, causas e remédios (1899). }\end{array}$ \\
\hline $\begin{array}{l}\text { Francis Galton } \\
(1822-1911)\end{array}$ & $\begin{array}{l}\text { Antropologista, } \\
\text { metereologista, } \\
\text { matemático e } \\
\text { estatístico. }\end{array}$ & Inglaterra & $\begin{array}{l}\text { Criador do termo Eugenia. Mais } \\
\text { conhecido pelo estudo da hereditariedade } \\
\text { e inteligência humana através de } \\
\text { instrumentação matemática e biológica. } \\
\text { Livro: Natural inheritance (1889). }\end{array}$ \\
\hline $\begin{array}{l}\text { Nina Rodrigues } \\
(1862-1906)\end{array}$ & $\begin{array}{l}\text { Professor de } \\
\text { Medicina Legal, } \\
\text { Bahia. }\end{array}$ & Brasil & $\begin{array}{l}\text { Teses sobre a degenerescência e } \\
\text { tendências ao crime dos negros e } \\
\text { mestiços. Para ele o negro e os mestiços } \\
\text { seriam as chagas da nossa nacionalidade. } \\
\text { Obras: Mestiçagem, degeneração e crime } \\
\text { (1899), Degenerescência física e mental } \\
\text { entre os mestiços nas terras quentes } \\
\text { (1899). }\end{array}$ \\
\hline
\end{tabular}




\begin{tabular}{|c|c|c|c|}
\hline $\begin{array}{l}\text { Euclides } \\
\text { Rodrigues } \\
\text { da Cunha } \\
(1866-1909)\end{array}$ & $\begin{array}{l}\text { Engenheiro, } \\
\text { cientista e literário, } \\
\text { Instituto de Obras } \\
\text { Contra Seca - IOC. }\end{array}$ & Brasil & $\begin{array}{l}\text { Mergulhado nos pressupostos e } \\
\text { preconceitos advindos do credo } \\
\text { cientificista: evolucionismo, }{ }^{2} \\
\text { determinismo climático e biológico e, } \\
\text { de uma forma mais geral, o positivismo. } \\
\text { Por esse caminho o conceito de sertão } \\
\text { era compreendido da forma mais } \\
\text { pejorativa possível, desqualificando a } \\
\text { terra e a humanidade a ela relacionada, } \\
\text { reconhecendo neles a impossibilidade } \\
\text { de qualquer desenvolvimento rumo à } \\
\text { civilização. Obra principal: Os sertões: } \\
\text { campanha de canudos (1902). }\end{array}$ \\
\hline $\begin{array}{l}\text { Oliveira Viana } \\
\text { (1883-1951) }\end{array}$ & $\begin{array}{l}\text { Professor da } \\
\text { Faculdade de Direito } \\
\text { no Rio de Janeiro. }\end{array}$ & Brasil & $\begin{array}{l}\text { A tese de que os bandeirantes paulistas } \\
\text { eram perfeitos arianos: altos, fortes, } \\
\text { loiros e de olhos claros. Segundo ele, } \\
\text { o país seria o resultado da vontade } \\
\text { e da energia das elites brancas, } \\
\text { racialmente superiores. Os negros e } \\
\text { índios, por outro lado, não haviam dado } \\
\text { "nenhum elemento de valor" à nossa } \\
\text { formação histórica e cultural. Uns e } \\
\text { outros se tornaram "massa passiva } \\
\text { e improgressiva". Obras: Populações } \\
\text { meridionais do Brasil (1920); Pequenos } \\
\text { estudos de psicologia social (1921); O } \\
\text { idealismo na evolução política do império } \\
\text { e da república (1922); Evolução do povo } \\
\text { brasileiro (1923); O caso do império } \\
\text { (1925); O Idealismo na constituição } \\
\text { (1927); Problemas de política objetiva } \\
\text { (1930); Raça e assimilação (1932); } \\
\text { Formation ethnique du Brésil coloniel } \\
\text { (1932); Problemas do direito corporativo } \\
\text { (1938); As novas diretrizes da política } \\
\text { social (1939). }\end{array}$ \\
\hline
\end{tabular}

Fonte: Adaptado de Buonicore (2005) e Oliveira (2002).

Como exemplo do papel do cientificismo no Brasil, temos as missões civilizatórias da Primeira República, que correspondem a "viagens associadas a projetos modernizadores: construções de ferrovias, avaliações da Inspetoria de Obras Contra as Secas, construções de linhas telegráficas". Verifica-se ainda um expressivo movimento com base na ideia de valorização do sertão, a exemplo da Missão Rondon,

2 Entendidas como interpretações reducionistas da teoria evolucionista. 
das expedições do Instituto Oswaldo Cruz e das viagens de Euclides da Cunha a Canudos e ao Amazonas. Segundo Lima (1999, p. 67):

Este movimento missionário, fortemente associado à expansão da presença do Estado, encontrou como atores sociais, agentes informados pelo cientificismo - quer na posição positivista ortodoxa, quer nas versões heterodoxas e em interpretações evolucionistas de cunho spenceriano.

Nesse panorama, destacamos as viagens médico-científicas de Arthur Neiva e Belisário Pena ao Norte e Nordeste do Brasil em 1912, por requisição da Inspetoria de Obras Contra as Secas, que caracterizam as populações do interior do país com base nas doenças, no isolamento, geográfico e cultural, no analfabetismo, na pobreza e na vocação a regredir. "De todas as expedições realizadas pelo Instituto Oswaldo Cruz, essa foi a de maior repercussão, nos meios intelectuais, médicos e políticos brasileiros”. (SÁ, 2009, p. 184-185)

Essas considerações têm em vista destacar o campo de representações do sertão na Primeira República. Para Lima (1999), sertão e viagem são termos que se interpenetram nas primeiras décadas republicanas no interior do país. Reinava entre intelectuais o sentimento de estar em uma missão: educar o povo brasileiro e, para isso, utilizavam-se dos meios institucionalizados: escolas, faculdades e jornais. Um exemplo marcante dessa prática é o uso da conferência pública entre letrados brasileiros da virada do século XIX para o século XX, meio utilizado para informar ao público ouvinte sobre assuntos literários e científicos em evidência. Tempo em que ciência e arte estavam em pleno processo de institucionalização no Brasil. (CAMPOS, 2010)

Em síntese, foram séculos de construção e reconstrução de representações de sertão que, a depender do período e dos acontecimentos sociais, difundiram, entre outras, ideias de deserto, incivilizada, nação, atraso e doença, que são o reflexo das estratégias de domínio e controle da elite e podem ser notadas até os dias de hoje, 
tendo em vista a estrutura da região que permanece pobre ao longo da história (Figura 2).

Figura 2 - Momentos históricos e principais ideias associadas ao sertão

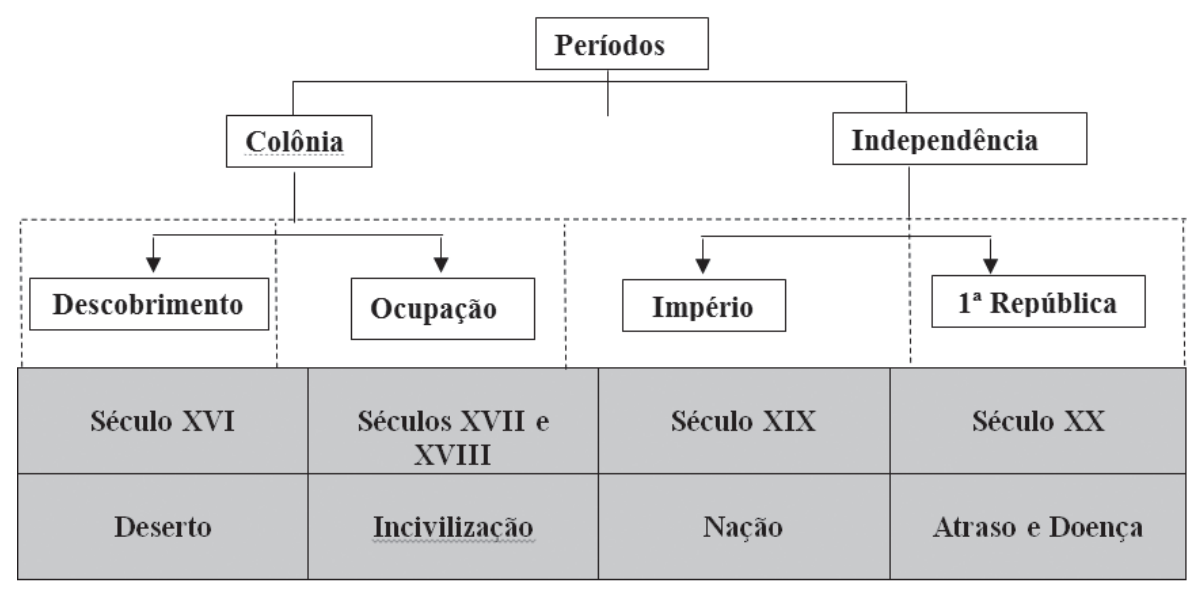

Fonte: Elaborada pelos autores.

Entende-se que a forma como se pensa a realidade material pode perpetuar ou transformar a conformação de desigualdades sociais construídas ao longo da história. Nesse ponto, impõe-se a discussão sobre as cidades Petrolina-PE e Juazeiro-BA, como referência do modelo de "desenvolvimento", considerando a implantação da agricultura irrigada voltada para o mercado internacional. Segundo Elias (2006, p. 34), de “imaginário trágico" para "desenvolvimento", é uma "[...] radical mudança do discurso sobre as possibilidades econômicas do semiárido, notadamente sobre os seus vales úmidos, e dos cerrados do Nordeste, construindo-se um novo imaginário social”.

Em relação à Petrolina-PE e Juazeiro-BA, a existência de mão de obra abundante e sol o ano inteiro para garantir a produção agrícola tem sido o discurso contemporâneo. (BARROS; COSTA; SAMPAIO, 2004) Segundo Sobel e Ortega (2007, p. 4): "Há pouco mais de três décadas, este território se apresentava como mais um dentre as diversas zonas de miséria situadas no sertão nordestino". Agora a região sertaneja é 
considerada um oásis para o agrobusiness, cuja prática produtiva difere, e muito, da prática agrícola tradicional. Enquanto a prática agrícola tradicional ou familiar tem técnicas simples de plantio e colheita, o agrobusiness utiliza a tecnologia de ponta, para atender às medidas de desempenho do modelo capitalista (excedentes, produtividade, lucro, escala de produção). O discurso tecnológico atrai pesquisadores, governo, bancos, órgãos internacionais e empresários, constituindo um quadro que pode tornar a agricultura familiar invisível. Guilhoto e colaboradores (2006) mostram que a agricultura familiar, além do alto nível de importância social, tem mais importância econômica que o agronegócio para o Brasil. Segundo os autores:

[...] o setor agropecuário familiar faz parte da história do Brasil e da própria humanidade. Sua influência foi reduzida ao longo dos séculos devido ao desenvolvimento tecnológico do próprio setor agropecuário e dos outros setores produtivos da economia. Assim, paulatinamente, o termo familiar tem sido associado a passado, atraso e pouca significância. (GUILHOTO et al. 2006, p. 356)

Teremos, assim, em um mesmo cenário a "agricultura científica" e a "agricultura tradicional" disputando a gestão das políticas públicas. Nesse quadro de divergência entre os setores, a "agricultura científica" atende a uma minoria organizada e capitalizada, que garante retorno financeiro, oposto à estrutura da "agricultura tradicional”, cuja maioria é desorganizada e descapitalizada, sem garantias de retorno financeiro. O discurso da "agricultura científica" passa a ser hegemônico, em detrimento da importância da "agricultura tradicional”, que possui fragilidade de organização para a promoção dos seus interesses, grande número de unidades heterogêneas, diversidade de estratégias produtivas e objetivos difusos. (ELIAS, 2006) 


\section{Petrolina-Juazeiro: um exemplo de contextualização e representação}

Petrolina localiza-se no extremo sudoeste do estado de Pernambuco, às margens do rio São Francisco, e era passagem obrigatória de boiadeiros que atravessavam o rio. Essa movimentação propiciou o surgimento de duas cidades, uma em cada margem do rio São Francisco: Petrolina, no estado de Pernambuco, e Juazeiro, na Bahia.

Em 1862, Petrolina torna-se freguesia, o que implicou prestígio e possibilidade de crescimento. Hoje, Petrolina e Juazeiro formam um grande polo comercial e agroindustrial impulsionado pela agricultura irrigada para o mercado externo. (FONSECA, 2008) Segundo Elias (2006 p. 32-33)

Se até a década de 1980 o conjunto da agropecuária nordestina permaneceu quase inalterado, a partir de então, se vislumbra a ocupação de novas fronteiras pelo agronegócio globalizado, em alguns lugares específicos dessa região. Estes passam a receber vultosos investimentos de algumas importantes empresas do setor, difundindo-se a agricultura científica.

Segundo Silva (2001), as ações que consolidam a agricultura científica voltada para o mercado externo em Petrolina e Juazeiro podem ser sintetizadas em quatro etapas: primeiros passos da fruticultura irrigada (1950-1975) no Submédio do Vale do São Francisco (SMVSF), a constituição do polo agroindustrial nos municípios Petrolina-PE e Juazeiro-BA e o início da fruticultura (1975-1985), a fruticultura e a formação de uma base exportadora no polo Petrolina/ Juazeiro (19851994), e a consolidação do complexo frutícola desse polo (1994-1999) (Tabela 2).

Instaura-se um ciclo que se irradia no mercado de serviços da região. No tocante a Petrolina-PE, destacam-se o Polo Médico, considerado o segundo do estado de Pernambuco, e a implantação de instituições de ensino público de nível superior, a saber, Faculdade de Ciências Sociais Aplicadas de Petrolina (Facape), Universidade 
Federal do Vale do São Francisco (Univasf) e Universidade do Estado de Pernambuco (UPE). Quanto a Juazeiro-BA, destacam-se a Universidade do Estado da Bahia (Uneb) e o mercado financeiro.

Quadro 2 - Síntese do processo de implantação da fruticultura no SMVSF

\begin{tabular}{|l|l|l|}
\hline PERÍODOS & ETAPAS & FATORES DETERMINANTES \\
\hline $1950-1975$ & $\begin{array}{l}\text { Primeiros passos da } \\
\text { fruticultura irrigada. }\end{array}$ & $\begin{array}{l}\text { Ação do estado em infraestrutura. Criação da CVSF, da } \\
\text { Suvale e da Superintendência do Desenvolvimento do } \\
\text { Nordeste (SUDENE). Empreendimentos pioneiros. } \\
\text { Projetos-pilotos de irrigação. }\end{array}$ \\
\hline $1975-1985$ & $\begin{array}{l}\text { A constituição do } \\
\text { polo agroindustrial } \\
\text { nos municípios } \\
\text { de Petrolina-PE e } \\
\text { Juazeiro-BA e o início } \\
\text { da fruticultura. }\end{array}$ & $\begin{array}{l}\text { Criação da Companhia de Desenvolvimento do Vale do } \\
\text { São Francisco e do Parnaíba (Codevasf). Implantação e } \\
\text { operação de projetos públicos de irrigação. Instalação } \\
\text { de agroindústrias. Empreendimentos pioneiros em } \\
\text { vitivinicultura. Instalação dos primeiros projetos de } \\
\text { fruticultura para exportação. }\end{array}$ \\
\hline $1985-1994$ & $\begin{array}{l}\text { A fruticultura e a } \\
\text { formação de uma } \\
\text { base exportadora } \\
\text { no polo Petrolina/ } \\
\text { Juazeiro. }\end{array}$ & $\begin{array}{l}\text { Infraestrutura de irrigação. Criação da Valexport. Crise do } \\
\text { Estado e do padrão de financiamento. Abertura comercial. } \\
\text { Integração com mercados regional e nacional de frutas. }\end{array}$ \\
\hline $\begin{array}{l}\text { Consolidação do } \\
\text { complexo frutícola } \\
\text { do polo Petrolina/ } \\
\text { Juazeiro. }\end{array}$ & $\begin{array}{l}\text { Crescimento do mercado interno de frutas frescas. } \\
\text { Especialização territorial em fruticultura. Crise de } \\
\text { endividamento de grandes empresas. Emergência de novos } \\
\text { atores sociais/formas de organização. }\end{array}$ \\
\hline $1999-$ & \multicolumn{2}{|l}{}
\end{tabular}

Fonte: Adaptado de Silva (2001).

O processo segue com a estruturação de símbolos da dinâmica capitalista, tais como shopping centers, prédios de luxo e aeroporto. Basta um passeio no local para constatar nas conversas de moradores o quanto as cidades são ou ficaram “ricas” em função da fruticultura irrigada. Símbolos do modelo capitalista estruturam o discurso dessas pessoas, que passam a projetar a cidade "que nada deve em relação às capitais de referência”, Recife-PE e Salvador-BA.

Trabalhos acadêmicos fundamentados no modelo desenvolvimentista informam os resultados da implantação da fruticultura irrigada, em Petrolina e Juazeiro, através de indicadores de melhorias, tais como crescimento econômico, renda, consumo e exportação. 
Tais indicadores resultam de uma estratégia de "cima para baixo" da política de modernização agrícola do governo militar, que privilegiou excessivamente as

[...] condições físicas locais favoráveis à produção em grande escala da agricultura irrigada, esquecendo-se, em consequência, de proporcionar o mesmo cuidado a outros fatores como, por exemplo, os relacionados à articulação e participação das comunidades locais em torno das políticas adotadas. (SOBEL; ORTEGA, 2007, p. 5)

O suporte tecnológico da Empresa Brasileira de Pesquisa Agropecuária (Embrapa) é fator de fundamental importância para o cenário construído pelas ações do Governo Federal. Em 23 de junho de 1975, por meio da Deliberação 0045/75, foi criado o Centro de Pesquisa Agropecuário do Trópico Semi-Árido (CPATSA), empresa pública vinculada ao Ministério da Agricultura e do Abastecimento, com o objetivo de promover o desenvolvimento rural do semiárido brasileiro. A questão é que qualquer análise que se faça do modelo, que propõe o "desenvolvimento", ele fica restrito a determinados segmentos da sociedade. Segundo Ramos (2002, p. 3-4):

Refletindo-se sobre as mudanças no uso agrícola às margens do rio São Francisco, encontramos a constituição de um moderno polo fruticultor irrigado e a inserção cada vez maior da região no comércio internacional de frutas. No entanto, as distintas oportunidades que se dão a colonos, pequenos e médios irrigantes, e grandes empresários agrícolas, têm reforçado as exclusões técnicas e políticas.

Nessa lacuna, encontram-se outros fenômenos a serem discutidos, entre os mais citados estão os excluídos da economia de mercado, o jogo de forças, as relações de trabalho, a indústria da seca, a concentração do poder econômico e político. Segundo dados do Atlas Brasil (2013), no período 1991-2000, em Petrolina: 
A renda per capita média do município cresceu $107,82 \%$ nas últimas duas décadas, passando de $\mathrm{R} \$ 291,15$, em 1991 para $\mathrm{R} \$$ 404,40, em 2000. A pobreza [...] diminuiu $18,36 \%$, passando de $54,5 \%$ em 1991 para 44,5\% em 2000. A desigualdade cresceu: o Índice de Gini passou de 0,63 em 1991 para 0,64 em 2000.

Na lógica capitalista, a região sertaneja Petrolina/Juazeiro “enriqueceu", haja vista o aumento da renda. Se considerarmos que índices como renda per capita, resultado da divisão entre produção local e número de habitantes da região, “[...] são explicações que nos expõem somente à descrição, à constatação ou mesmo a interpretação dos fatos, sem que se procure desvendar os mecanismos sociais que os engendram” (FRANCO, 2004, p. 177), temos uma lacuna científica que necessita ser preenchida. Segundo Chauí (2004, p. 13):

[...] uma teoria exprime, por meio de ideias, uma realidade social e histórica determinada, e o pensador pode ou não estar consciente disso. Quando sabe que suas ideias estão enraizadas na história, pode esperar que elas ajudem a compreender a realidade de onde surgiram. Quando, porém, não percebe a raiz da história de suas ideias e imagina que elas serão verdadeiras para todos os tempos e todos os lugares, corre o risco de estar, simplesmente, produzindo uma ideologia.

Nessa perspectiva, a crítica ao que produz deve ser vista como uma constante que confirma a tese de que todo conhecimento é passível de "polifasia cognitiva", em outras palavras, "o saber não se desloca do contexto de sua produção, dos interesses e motivos que estão ligados a uma pessoa humana, a uma cultura humana." (JOVECHELOVITCH, 2004, p. 21) Segundo a autora:

Trata-se então de entender a forma que o saber assume enquanto representação e aquilo que expressa enquanto sistema psicossocial firmemente radicado, em um contexto social. Trata-se também de entender como a variabilidade das formas de saber se realiza nas esferas públicas e como ela é tratada. Isso porque enquanto alguns saberes gozam de 
credenciais epistemológicas plenas, reconhecimento e legitimidade, outros são vistos como distorções, superstição e erro. Resta saber se essa distinção parte de uma característica interna dos saberes ou de determinantes sociais mais amplos que conferem poder a alguns saberes e pelo mesmo movimento desapropriam outros de qualquer reconhecimento. (JOVECHELOVITCH, 2004, p. 21)

Diante do exposto, esse trabalho fundamentado pela teoria das representações sociais visa entender a complexidade do cotidiano pensando em opostos, dicotomias e desigualdades sociais. Segundo Arruda (2005, p. 231):

A TRS, como uma antropologia do mundo contemporâneo (MOSCOVICI, 1978), lida com as maneiras como os grupos dão sentido ao real, elaborando-o e explicando-o para si mesmos, para se comunicarem e funcionarem cotidianamente. Trata-se de um pressuposto da teoria, o da construção social da realidade; socialmente erigida e compartilhada, esta se dá em cada espaço social, se faz em códigos sociais, a partir do olhar que tal espaço e a experiência/informação/afetos do sujeito aí posto lhe facultam projetar sobre o objeto representado. A representação social tem pertença. O corolário deste pressuposto é que toda representação é representação de alguém e de alguma coisa (JODELET, 2000). Isto implica em que os grupos fazem interpretações 'legais' do mundo à sua volta, que são as representações sociais, e o/a pesquisador/, como um/a antropólogo/a, as analisa para interpretá-las à luz da ciência [...].

Essa investigação das representações sociais de sertão entre moradores das cidades sertanejas Petrolina-PE e Juazeiro-BA e entre estudantes-professores de licenciatura em História e Geografia entende que as mudanças da região decorrentes do acelerado desenvolvimento econômico e tecnológico despontam como rico cenário de investigação no campo da psicologia social. "Isto em função de ensejar a exploração da medida em que as transformações políticas, 
econômicas, tecnológicas, sociais, culturais, deixaram suas marcas no cotidiano das pessoas.” (PECORA; SÁ, 2008, p. 319)

\section{Considerações finais}

O estudo das representações sociais persegue a transformação do pensamento social e os seus desdobramentos segundo o grupo que fala. (ARRUDA, 2009) Segundo Jodelet (2001, p. 32-33):

[...] três perguntas podem ser formuladas: 'Quem sabe e de onde sabe?', 'O que e como sabe?' e 'Sobre o que se sabe e com que efeito?' [...] o lugar, a posição social que eles ocupam ou as funções que assumem determinam os conteúdos representacionais e sua organização, por meio da relação ideológica que mantêm com o mundo social (PLON, 1972), as normas institucionais e os modelos ideológicos aos quais obedecem.

Figura 3 - Conteúdo das representações sociais

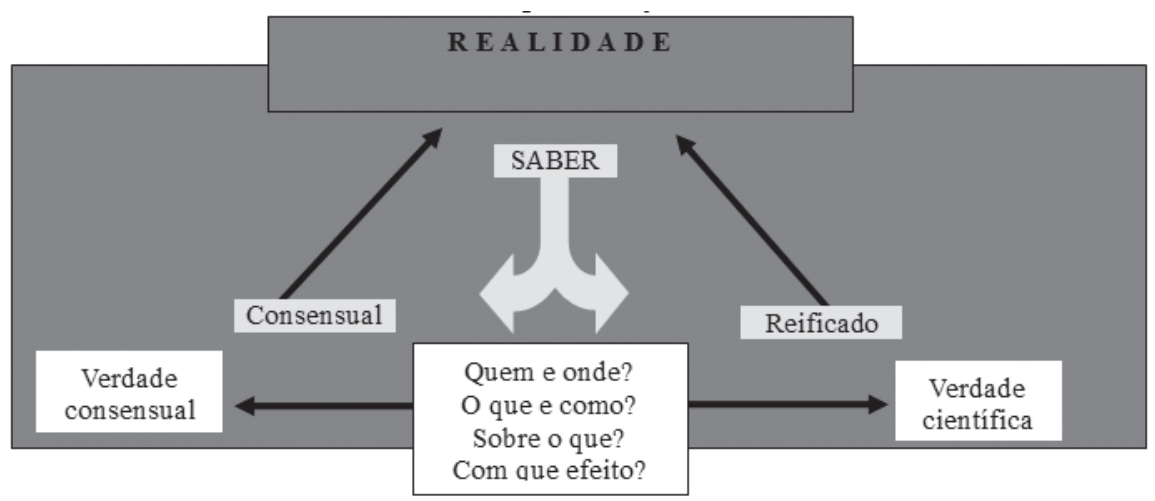

Fonte: Adaptada de Jodelet (2001).

Podemos fazer uma reflexão a partir da figura anterior. Para lidar com a realidade, o sujeito constrói conhecimento. Essa construção pode ser empírica ou científica, "depende da posição social que o sujeito do conhecimento ocupa”. Considerando o poder de legitimação da construção do conhecimento científico, o saber propaga-se como 
forma de lidar com a realidade. Uma vez aceito como verdade, "consensual” ou "reificada", concretiza-se em espaço público.

\section{Referências}

ARRUDA, A. Despertando do pesadelo: a interpretação. In: MOREIRA, A. S. P.; CAMARGO, B. V.; JESUINO, J. C.; NÓBREGA, S. M. Perspectivas teóricometodológicas em representações sociais. João Pessoa: Universitário UFPB, 2005. p. 229-258.

ARRUDA, A. Teoria das representações sociais e ciências sociais: trânsito e atravessamentos. Sociedade e Estado, Brasília, DF, v. 24, n. 3. p. 739-766, 2009.

ARRUDA, A. Representando a alteridade. Petrópolis: Vozes, 1998.

ATLAS BRASIL. Atlas do Desenvolvimento Humano no Brasil, [S.I.], 2013. Disponível em: < http://www.atlasbrasil.org.br/2013/pt/perfil_m/petrolina_pe>. Acesso em: 23 nov. 2015.

BARROS, E. S.; COSTA, E. F.; SAMPAIO, Y. Análise de eficiência das empresas agrícolas do pólo Petrolina/Juazeiro utilizando a fronteira paramétrica Translog. Revista de Economia e Sociologia Rural, Brasília, DF, v. 42, n. 4, p. 597-614. 2004. Disponível em: <http://www.scielo.br/scielo.php?script=sci_ arttext\&pid=S0103-20032004000400004>. Acesso em: 8 fev. 2012.

BUONICORE, A. C. Reflexões sobre o marxismo e a questão racial: ( $2^{a}$ parte). Revista Espaço Acadêmico, Maringá, n. 53, out. 2005. Disponível em: <http:// www.espacoacademico.com.br/053/53buonicore.htm>. Acesso em: 13 abr. 2011 CÂNDIDO, A. O romantismo no Brasil. São Paulo: Humanitas, 2004.

CHAUÍ, M. S. O que é ideologia. São Paulo: Brasiliense, 2004.

COELHO, L. R.; SANTOS, L. S. Representação social de sertão e discurso nos Jornais de Salvador. Revista Internacional de Folkcomunicação, Ponta Grossa, v. 1, n. 12, 2005. Disponível em: <http://www.eventos.uepg.br/ojs2_revistas/ index. php?journal=folkcom\&page =article\&op=viewFile\&path \%5B\%5D=642\&p ath $\% 5 B \% 5 D=469>$. Acesso em: 15 jul. 2009.

CAMPOS, R. de D. Um intelectual viajante: Floriano de Lemos no sertão paulista (1926-1930). Revista Brasileira de História, Marília, v. 30, n. 60, 2010. Disponível em: <http://www.redalyc.org/src/inicio/ArtPdfRed. jsp? iCve=26319122009 $>$. Acesso em: 7 fev. 2012. 
DUARTE, R. Seca, pobreza e políticas públicas no nordeste do Brasil. Pobreza, desigualdade social e cidadania. Los límites de las políticas sociales en América Latina. CLACSO. Buenos Aires, 2001. Disponível em: <http://biblioteca.clacso. edu.ar/clacso/gt/20101030020924/16duarte.pdf>. Acesso em: 9 de ago. 2009.

ELIAS, D. Ensaios sobre os espaços agrícolas de exclusão. Revista NERA, São Paulo, ano 9, n. 8, p. 29-51, jan./jun. 2006. Disponível em: <http://www4.fct. unesp.br/nera/revistas /08/Elias.PDF>. Acesso em: 13 set. 2009.

FRANCO, M. L. P. B. Representações sociais, ideologia e desenvolvimento da consciência. Caderno de Pesquisa, São Paulo, v. 34, n. 121, p. 169-186, 2004.

FONSECA, H. Pernambucânia: o que há nos nomes das nossas cidades. 2. ed. Recife: CEPE, 2008.

GOMES, P. P. P. O sertão dilacerado: outras histórias de Deus e o Diabo na terra do sol. Lua Nova, Água Branca, n. 74, p. 11-34, 2008.

GUEDES, P. H. M. Q. A colonização do sertão da Paraíba: agentes produtores do espaço e contatos interétnicos (1650-1730). 2006. 157 f. Dissertação (Mestrado em Geografia) - Centro de Ciências Exatas e da Natureza, Universidade Federal da Paraíba, João Pessoa, 2006.

GUILHOTO, J. M et al. A importância do agronegócio familiar no Brasil. Revista de Economia e Sociologia Rural, Brasília, DF, v. 44, n. 3, p. 355-382, jul./set. 2006.

IBGE. Atlas das representações literárias de regiões brasileiras: Brasil meridional: volume 1. Rio de Janeiro, 2006. Disponível em: <ftp://geoftp.ibge. gov.br/atlas/atlas_representacoe_literarias/vol_1_brasil_meridional.pdf>. Acesso em: 24 nov. 2015.

INSTITUTO DE PESQUISA ECONÔMICA APLICADA. A década inclusiva (2001-2011): desigualdades, pobreza e políticas de renda. [Brasília, DF], 2012. Disponível em: <http://www.ipea.gov.br/agencia/images/stories/PDFs/comunicado/120925_ comunicadodoipea155_v5.pdf>. Acesso em: 24 nov. 2015.

JODELET, D. As representações sociais. Rio de Janeiro: Ed. UERJ, 2001.

JOVECHELOVITCH, S. Psicologia social, saber, comunidade e cultura, Londres: London School of Economics and Politcal Science, 2004. Disponível em: <http://www.scielo.br/pdf/psoc/v16n2/a04v16n2.pdf>. 
ALENCAR, J. O Sertanejo, [S.I.], [19-?]. Disponível em: <http://www. dominiopublico.gov.br/pesquisa/DetalheObraForm.do? select_action =\&co_ obra=1848>. Acesso em: 9 fev. 2012.

LIMA, R. Mundar o sertão: ou quando o Jaguaribe virou açude no Ceará. Avá, [S.I.], v. 13, n. 1, p. 1, jul. 2008.

LIMA, N. T. Um sertão chamado Brasil: intelectuais e representação geográfica da identidade nacional. Rio de Janeiro: Revan: IUERJ, 1999.

MATTAR VILELA, J. Moral da política e antropologia das relações de poder no sertão de Pernambuco, Lua Nova, São Paulo, n. 79, p. 163-199, 2010.

OLIVEIRA, R. de. Euclides da Cunha, Os sertões e a invenção de um Brasil profundo. Revista Brasileira de História, São Paulo, v. 22, n. 44, 2002 . p. 511-537.

PECORA, A. R.; SÁ, C. P. Memórias e representações sociais da cidade de Cuiabá, ao longo de três gerações. Psicologia: reflexão e crítica, v. 21, n. 2, p. 319-325, 2008. Disponível em: <wWw.scielo.br/pdf/prc/v21n2/a18v21n2.pdf>. Acesso em: 8 fev. 2012.

ROCHA, J. D.; BURSZTYN, M. Políticas públicas territoriais e sustentabilidade no semi-árido brasileiro: busca do desenvolvimento via arranjos produtivos locais. Revista Ciência de Administração, Fortaleza, v. 14, n. 2, p. 263-278, dez. 2008. Disponível em: <http://www.unifor.br/notitia/file/2495.pdf>. Acesso em: 4 jul. 2009.

RAMOS, S. F. Uso do território brasileiro e sistemas agrícolas: a fruticultura irrigada em Petrolina (PE) / Juazeiro (BA), In: ENCONTRO NACIONAL DE GEOGRAFIA AGRÁRIA. 16., 2002. Petrolina. Anais... Petrolina: UPE/UFPE, 2002. p. 391-393.

SÁ, A. F. A. O cangaço nas histórias em quadrinhos. Diálogos Latinoamericanos, Aarhus, n. 8, p. 49-75, 2003. Disponível em: <http://redalyc.uaemex.mx/ pdf/162/16200804.pdf>. Acesso em: 8 fev. 2012.

SÁ, D. M. Uma interpretação do Brasil, como doença e rotina: a repercussão do relatório médico de Arthur Neiva e Belisário Penna (1917-1935). História, Ciências, Saúde - Manguinhos, Rio de Janeiro, v. 16, p. 183-203, 2009. Suplemento.

SILVA, R. M. A. Entre o combate à seca e a convivência com o semi-árido: políticas públicas e transição paradigmática. Revisa Econômica do Nordeste, Fortaleza, v. 38, n. 3, p. 446-485, jul./set. 2007. Disponivel em: <http:// www.bnb.gov.br/projwebren /exec/artigo RenPDF.aspx?cd_artigo_ren=1042>. Acesso em: 30 jul. 2009. 
SILVA, P. C. G. Articulação dos interesses públicos e privados no pólo Petrolina-PE/Juazeiro-BA: em busca de espaço no mercado globalizado de frutas frescas. Campinas, 2001. 245 f. Tese (Doutorado em Economia) Instituto de Economia, Universidade Estadual de Campinas, 2001. Disponível em: <http://libdigi.unicamp.br/document/?code=vtls000232434 >. Acesso em: 13 jul. 2009.

SOBEL, T. F.; ORTEGA, A. C. Evolução e situação atual do Pólo PetrolinaJuazeiro: uma análise a partir dos indicadores sócio-econômicos. In: CONGRESSO DA SOCIEDADE BRASILEIRA DE ECONOMIA, ADMINISTRAÇÃO E SOCIOLOGIA RURAL, 45., 2007, Londrina. Anais... Londrina : SOBER, 2007. Disponível em: <http://www.sober.org.br/palestra/6/954.pdf> Acesso em: 22 abr. 2010 